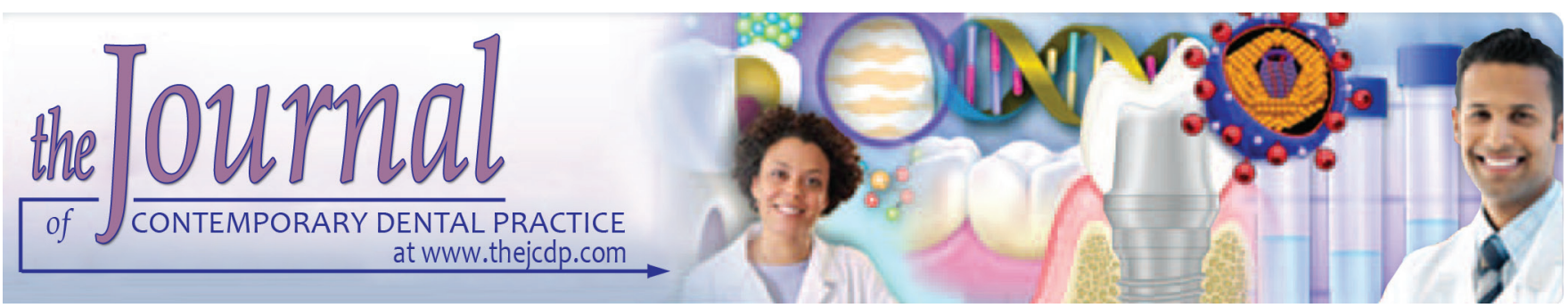

\title{
Assessment of lons released from Three Types of Orthodontic Brackets immersed in Different Mouthwashes: An in vitro Study
}

${ }^{1}$ Mohammed Nahidh, ${ }^{2}$ Noor MH Garma, ${ }^{3}$ Esraa S Jasim

\begin{abstract}
Aim: Herbs are used widely in medicine. The purpose of the present study was to assess the ion release from gold-plated orthodontic bracket compared with other stainless steel brackets, and based on the findings of the study, the orthodontists can choose the most biocompatible brackets and mouthwashes useful in the clinical practice.
\end{abstract}

Materials and methods: A total of 150 orthodontic brackets from Orthotechnology ${ }^{\mathrm{TM}}$ Company, USA (50 stainless steel one-piece brackets, 50 stainless steel two-piece brackets, and 50 gold brackets) were immersed in four mouthwashes in addition to distilled water. Ten of each type of brackets in every media were immersed under $37^{\circ} \mathrm{C}$ for 45 days. lons released in these mouthwashes were measured, and comparisons among different bracket types and among various mouthwashes were done by one-way analysis of variance (ANOVA) and then with Games-Howell tests.

Results: Increased amounts of ions released in herbal mouthwashes were recorded in gold and two-piece brackets in comparison with one-piece stainless steel brackets.

Conclusion: Herbal mouthwashes must be used with caution as they showed an increased amount of ions released in comparison with chlorhexidine. One-piece stainless steel bracket system is the most compatible bracket type, as they released the least amount of ions.

Clinical significance: One-piece stainless steel brackets are better than two-piece brackets in terms of ions released.

Keywords: Corrosion, Herbal mouthwashes, lon release.

How to cite this article: Nahidh M, Garma NMH, Jasim ES. Assessment of lons released from Three Types of Orthodontic Brackets immersed in Different Mouthwashes: An in vitro Study. J Contemp Dent Pract 2018;19(1):73-80.

\footnotetext{
${ }^{1-3}$ Department of Orthodontics, College of Dentistry, University of Baghdad, Baghdad, Iraq
}

Corresponding Author: Mohammed Nahidh, Department of Orthodontics, College of Dentistry, University of Baghdad Baghdad, Iraq, Phone: +009647702551616, e-mail: m_nahidh 79@yahoo.com
Source of support: Nil

Conflict of interest: None

\section{INTRODUCTION}

After the introduction of edgewise brackets by Angle, ${ }^{1}$ a wide range of brackets were introduced and made from various alloys, such as stainless steel (iron, chromium, and nickel), titanium, and cobalt-chromium alloy. ${ }^{2}$ One type of metal bracket is plated with $24 \mathrm{~K}$ gold to make brackets brighter than other metal brackets and enhance wear resistance. These brackets are fabricated by one of three methods: Casting, milling, and metal injection molding (MIM). ${ }^{3-5}$

The biocompatibility of dental alloys has been investigated over the past two decades. The introduction of metal ions into the human body affords the additional risk to health, as these ions may be released in different places and at different levels depending on the characteristics and solubility of the products containing them. ${ }^{6}$

The resistance to corrosion, a substantial aspect of biocompatibility, could be affected by several factors. The first depends on the type of alloy, manufacturing process, and surface characteristics of the piece. ${ }^{7}$ The second attributed to the environment in which the piece is inserted. The third referred to the use or aging of the alloy. ${ }^{8}$ On these considerations, it is logical to assume that one-piece system brackets have increased corrosion resistance and are free from corrosion risk associated with galvanic couple of brazing alloys with the stainless steel occurring in conventional two-piece brackets.

During the course of orthodontic treatment that may last more than 1 year, development of white spot lesions (WSLs) is possible unless very good oral hygiene is maintained along the period of treatment. To prevent its development, right and careful brushing of teeth with 
fluoridated dentifrice must be explained to the patients, also, use of mouthwash (fluoridated or herbal), bonding brackets with a glass ionomer cement, topical application of stannous fluoride, and casein phosphopeptideamorphous calcium phosphate may play a role in reducing the incidence of WSLs., ${ }^{9,10}$

Chlorhexidine mouthwash is mostly prescribed due to its effect on bacterial cell membrane integrity. It acts on Gram-negative and Gram-positive bacteria, fungi, yeasts, and viruses. ${ }^{11}$ Although it is potent, it has many side effects like brown staining of teeth, disturbance of taste, mucosal desquamation, and increased calculus deposition. ${ }^{12}$ Again for biocompatible reasons, the main substitute of chlorhexidine is herbal mouthwashes. They do not have the side effects of chemical mouthwashes and can be used for the prevention of WSLs and strengthening of enamel, such as Siwak, Aloe vera (ALO), and cinnamon. The use of mouthwashes is associated with ions released in saliva. In vitro studies ${ }^{13-18}$ were performed to estimate the concentrations of different ions, such as $\mathrm{Ni}, \mathrm{Cr}, \mathrm{Cu}$, $\mathrm{Fe}$, and $\mathrm{Mn}$ in chemical (fluoridated and nonfluoridated) and some herbal mouthwashes.

To the best of authors' knowledge, gold-plated bracket has not been investigated in regard to ion release. Therefore, the aim of this study was first to assess the ion release from gold-plated bracket compared with common stainless steel brackets; and second, to estimate herbal mouthwashes with regard to ion release in an attempt to be able to choose more biocompatible brackets and mouthwashes in the clinical practice.

\section{MATERIALS AND METHODS}

\section{Sample}

- The sample consisted of a total of 150 maxillary premolar orthodontic brackets (Roth type, 0.022 inch slot, Orthotechnology Co., USA). The brackets were

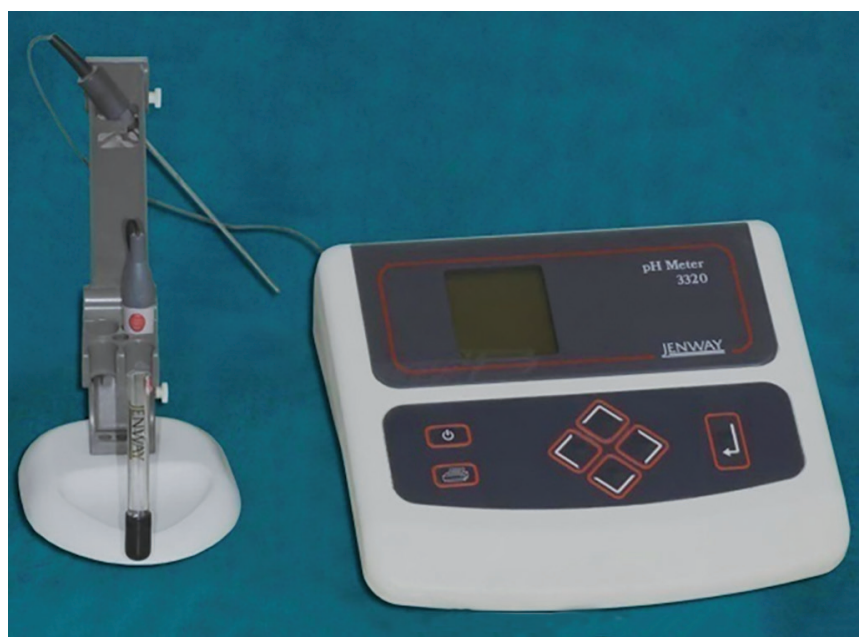

Fig. 1: $\mathrm{pH}$ meter divided into three groups according to their types: 50 brackets Votion ${ }^{\mathrm{TM}}$ (two-pieces base) and 50 brackets Pinnacle $^{\mathrm{TM}}$ (one-piece bracket system) both types utilizing MIM, and 50 brackets Marquis TruGold ${ }^{\mathrm{TM}}$ utilizing casting production process.

- Four mouthwashes in addition to the control (distilled water [DW]). They were as follows:

- DW (Iraq), pH: 7.04.

- Aloe Dent ${ }^{\circledR}$ mouthwash (ALO mouthwash, Optima ${ }^{\circledR}$, Italy), pH: 5.17.

- Aloe Dent ${ }^{\circledR}$ mouthwash with fluoride [ALO mouthwash with fluoride (ALOF), Optima ${ }^{\circledR}$, Italy], pH: 5.46 .

- Jăsön ${ }^{\circledR}$ mouthwash (orange cinnamint, Nutri Smile ${ }^{\circledR}$, United States A), pH: 2.83.

- Zordyl ${ }^{\circledR}$ mouthwash (chlorhexidine gluconate $0.2 \% \mathrm{w} / \mathrm{v}$, Julphar ${ }^{\circledR}$, United Arab Emirates), pH: 7.10 .

\section{Methods}

The three metallic orthodontic bracket types were first placed in an acetone solution for 2 minutes for surface cleansing, ${ }^{17}$ and the $\mathrm{pH}$ of each mouthwash and the DW was measured using pH meter (JENWAY, model 3320, Cyprus) as shown in Figure 1.

The brackets were subdivided into five subgroups (for each main type) according to the mouthwash, 10 per each subgroup and dipped separately in a $20 \mathrm{~mL}$ glass beaker containing $15 \mathrm{~mL}$ of the specific mouthwash and kept in incubator at $37^{\circ} \mathrm{C}$ for 45 days. ${ }^{13,14}$

The samples were subjected to atomic absorption spectrophotometer (Flame Atomic Absorption Spectrophotometer-Analytik Jena/NOV AA-300, Germany) for the scientific reading of nickel, copper, and chromium ion release (Fig. 2). The concentration of manganese was determined using furnace atomic absorption spectrophotometer (Fig. 3).

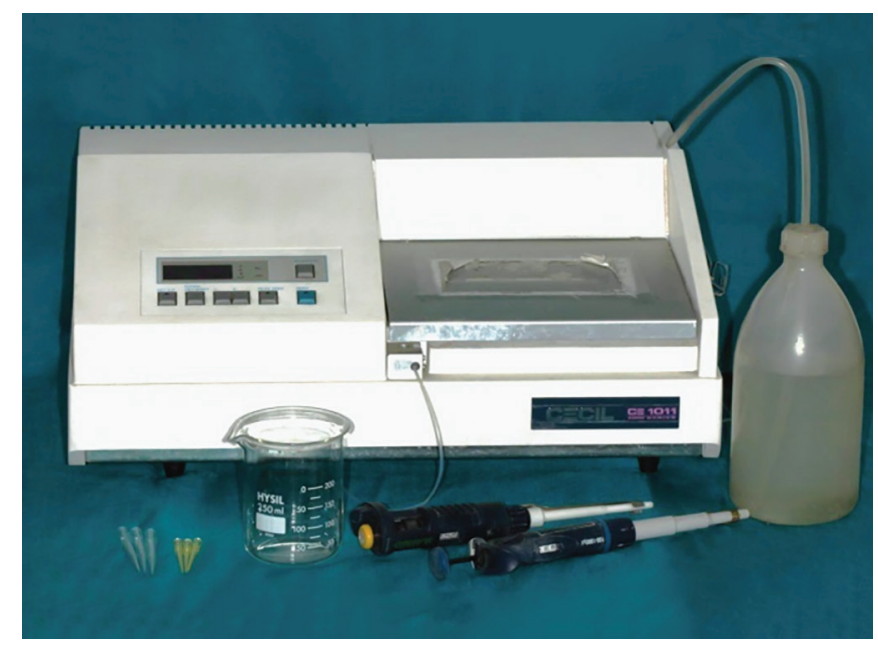

Fig. 2: Flame atomic absorption spectrophotometer 


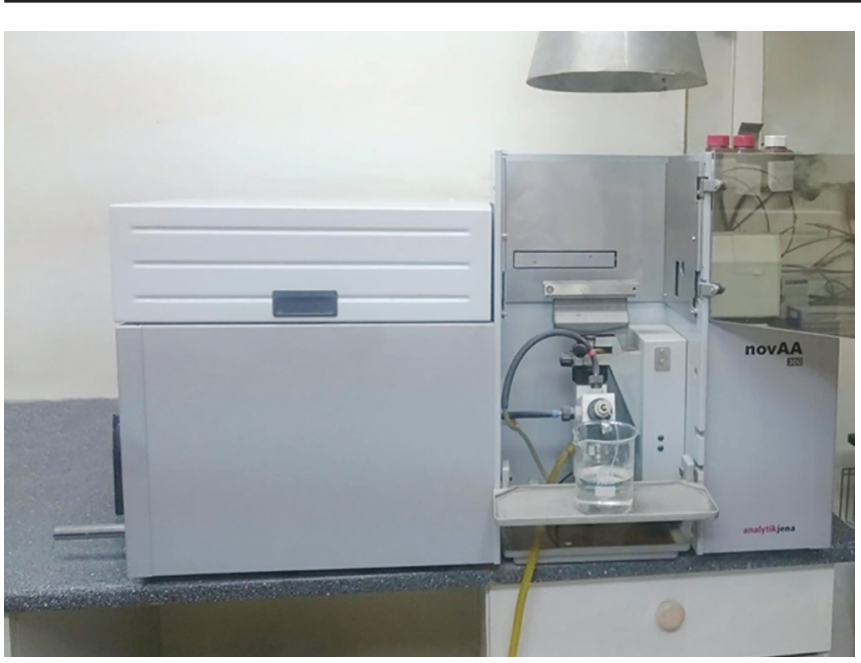

Fig. 3: Furnace atomic absorption spectrophotometer

Iron was analyzed by flameless spectrophotometer (Cecil 1011, Germany) with iron kit (Liquicolor, Human diagnostics Worldwide, Germany). All of these procedures were performed in the laboratories of poisoning center in Iraq.

For more study interpretation and further understanding, X-ray diffraction (XRD) instrument (Lab X-XRD-6000 Shimadzu/Pure Faculty of Education Sciences) was used to analyze bracket material components.

\section{Statistical Analyses}

The collected data were analyzed using Statistical Package for the Social Sciences program, version 21 . The analyses including descriptive statistics (means and standard deviation) and inferential statistics (one-way ANOVA test) were used to analyze the differences among mean ion concentrations in different mouthwashes and among bracket types. Games-Howell test was used for multiple group comparisons if ANOVA revealed a significant difference.

\section{RESULTS}

\section{Results of Ion Release}

Three different types of orthodontic brackets from the same company have been subjected to four different mouthwashes to measure the amount of ion release in addition to DW as a control group. The ions measured in this study were $\mathrm{Ni}, \mathrm{Cr}, \mathrm{Cu}, \mathrm{Fe}$, and $\mathrm{Mn}$.

Table 1 shows the descriptive statistics and comparison of different ions released from different brackets in each mouthwash and among different mouthwashes for the same brackets. In general, there was high statistically significant difference in ion release among different types of mouthwashes for each type of bracket. Games-Howell test revealed mostly high significant difference between two types of mouthwashes (Table 2).

Comparing the ions released from different brackets, Table 1 revealed statistically high difference except for $\mathrm{Cr}$ in DW, ALOF, and cinnamon. Table 3 shows the difference between two types of brackets in different mouthwashes, and there was high significant difference except for $\mathrm{Cr}$, $\mathrm{Mn}$, and $\mathrm{Cr}$ in DW.

Table 1: Descriptive statistics and comparison of the ions released $(\mu \mathrm{g} / \mathrm{L})$ for different brackets in various mouthwashes

\begin{tabular}{|c|c|c|c|c|c|c|}
\hline \multirow[b]{3}{*}{ lons } & \multirow[b]{3}{*}{ Mouthwashes } & \multicolumn{3}{|c|}{ Descriptive statistics } & \multirow{2}{*}{\multicolumn{2}{|c|}{ Comparison }} \\
\hline & & Pinnacle & Votion & Gold & & \\
\hline & & Mean $\pm S D$ & Mean $\pm S D$ & Mean $\pm S D$ & f-test & $p$-value \\
\hline \multirow[t]{7}{*}{$\mathrm{Cr}$} & DW & $24.60 \pm 2.17$ & $26 \pm 0.94$ & $24.8 \pm 2.10$ & 1.720 & 0.198 \\
\hline & $\mathrm{CHX}$ & $9.80 \pm 1.55$ & $35.6 \pm 5.72$ & $25.8 \pm 1.23$ & 17.902 & 0 \\
\hline & ALOF & $264.00 \pm 19.55$ & $268 \pm 25.30$ & $182 \pm 7.89$ & 97.473 & 0 \\
\hline & ALO & $15.80 \pm 1.81$ & $39 \pm 3.83$ & $25.8 \pm 3.22$ & 0.867 & 0.432 \\
\hline & CINN & $15.80 \pm 2.04$ & $25.8 \pm 1.23$ & $33.6 \pm 1.96$ & 0.425 & 0.658 \\
\hline & f-test & 1547.268 & 812.648 & 2909.070 & & \\
\hline & p-value & 0 & 0 & 0 & & \\
\hline \multirow[t]{7}{*}{$\mathrm{Ni}$} & DW & $104.40 \pm 9.92$ & $122 \pm 10.59$ & $148 \pm 24.40$ & 138.943 & 0 \\
\hline & $\mathrm{CHX}$ & $15.80 \pm 3.97$ & $84.4 \pm 5.23$ & $46.6 \pm 5.60$ & 475.470 & 0 \\
\hline & ALOF & $323.50 \pm 17.00$ & $350 \pm 14.91$ & $228 \pm 15.49$ & 723.569 & 0 \\
\hline & ALO & $98.80 \pm 6.84$ & $126 \pm 10.75$ & $156 \pm 10.75$ & 78.908 & 0 \\
\hline & CINN & $48.40 \pm 4.40$ & $160 \pm 33.33$ & $254 \pm 28.75$ & 548.150 & 0 \\
\hline & f-test & 1545.765 & 346.680 & 181.487 & & \\
\hline & p-value & 0 & 0 & 0 & & \\
\hline \multirow[t]{7}{*}{$\mathrm{Fe}$} & DW & $32.50 \pm 5.40$ & $100 \pm 14.91$ & $31 \pm 15.06$ & 65.176 & 0 \\
\hline & $\mathrm{CHX}$ & $132 \pm 12.29$ & $346 \pm 17.13$ & $92 \pm 18.14$ & 164.406 & 0 \\
\hline & ALOF & $113 \pm 7.89$ & $244 \pm 10.75$ & $100 \pm 14.91$ & 475.825 & 0 \\
\hline & ALO & $234 \pm 11.74$ & $546 \pm 45.51$ & $528 \pm 24.40$ & 89.090 & 0 \\
\hline & CINN & $324 \pm 18.97$ & $1026 \pm 14.30$ & $10362 \pm 133.40$ & 110.541 & 0 \\
\hline & f-test & 867.397 & 2222.112 & 54104.270 & & \\
\hline & $p$-value & 0 & 0 & 0 & & \\
\hline
\end{tabular}

(Cont'd...) 
(Cont'd...)

\begin{tabular}{|c|c|c|c|c|c|c|}
\hline \multirow[b]{3}{*}{ Ions } & \multirow[b]{3}{*}{ Mouthwashes } & \multicolumn{3}{|c|}{ Descriptive statistics } & \multirow{2}{*}{\multicolumn{2}{|c|}{ Comparison }} \\
\hline & & Pinnacle & Votion & Gold & & \\
\hline & & Mean $\pm S D$ & Mean $\pm S D$ & Mean $\pm S D$ & $f$-test & $p$-value \\
\hline \multirow[t]{7}{*}{$\mathrm{Mn}$} & DW & $0.15 \pm 0.04$ & $0.168 \pm 0.02$ & $0.162 \pm 0.01$ & 143.266 & 0 \\
\hline & $\mathrm{CHX}$ & $0.09 \pm 0.03$ & $0.22 \pm 0.04$ & $0.086 \pm 0.01$ & 88.354 & 0 \\
\hline & ALOF & $0.43 \pm 0.03$ & $0.492 \pm 0.02$ & $0.598 \pm 0.03$ & 328.236 & 0 \\
\hline & ALO & $0.53 \pm 0.03$ & $0.706 \pm 0.03$ & $0.832 \pm 0.07$ & 89.889 & 0 \\
\hline & CINN & $0.13 \pm 0.02$ & $0.15 \pm 0.02$ & $0.25 \pm 0.02$ & 468.545 & 0 \\
\hline & f-test & 457.080 & 933.107 & 678.728 & & \\
\hline & $p$-value & 0 & 0 & 0 & & \\
\hline \multirow[t]{7}{*}{$\mathrm{Cu}$} & DW & $15.80 \pm 1.55$ & $16.2 \pm 2.15$ & $15.4 \pm 2.07$ & 251.117 & 0 \\
\hline & $\mathrm{CHX}$ & $6.40 \pm 1.07$ & $34 \pm 3.33$ & $9 \pm 0.67$ & 162.383 & 0 \\
\hline & ALOF & $534.40 \pm 13.26$ & $634 \pm 27.16$ & $669 \pm 20.25$ & 51311.314 & 0 \\
\hline & ALO & $832 \pm 32.93$ & $1030 \pm 14.91$ & $1154 \pm 19.55$ & 107.398 & 0 \\
\hline & CINN & $12.40 \pm 1.07$ & $21.4 \pm 2.17$ & $50.2 \pm 9.27$ & 127.381 & 0 \\
\hline & f-test & 5787.567 & 10993.368 & 15034.990 & & \\
\hline & $p$-value & 0 & 0 & 0 & & \\
\hline
\end{tabular}

CHX: Chlorhexidine; CINN: Cinnamon; SD: Standard deviation

Table 2: Comparison of ions released between two types of mouthwashes using Games-Howell test

\begin{tabular}{|c|c|c|c|c|c|c|c|}
\hline \multirow[b]{2}{*}{ Bracket types } & \multirow[b]{2}{*}{ Mouthwashes } & & $\mathrm{Cr}$ & $\mathrm{Ni}$ & $\mathrm{Fe}$ & $M n$ & $\mathrm{Cu}$ \\
\hline & & & \multicolumn{5}{|l|}{$p$-value } \\
\hline \multirow[t]{10}{*}{ Pinnacle } & DW & $\mathrm{CHX}$ & 0 & 0 & 0 & 0.002 & 0 \\
\hline & & ALOF & 0 & 0 & 0 & 0 & 0 \\
\hline & & ALF & 0 & 0.595 & 0 & 0 & 0 \\
\hline & & CINN & 0 & 0 & 0 & 0.435 & 0 \\
\hline & $\mathrm{CHX}$ & ALOF & 0 & 0 & 0.007 & 0 & 0 \\
\hline & & ALF & 0 & 0 & 0 & 0 & 0 \\
\hline & & CINN & 0 & 0 & 0 & 0.004 & 0 \\
\hline & ALOF & ALF & 0 & 0 & 0 & 0 & 0 \\
\hline & & CINN & 0 & 0 & 0 & 0 & 0 \\
\hline & ALF & CINN & 1 & 0 & 0 & 0 & 0 \\
\hline \multirow[t]{10}{*}{ Votion } & DW & $\mathrm{CHX}$ & 0.003 & 0 & 0 & 0.007 & 0 \\
\hline & & ALOF & 0 & 0 & 0 & 0 & 0 \\
\hline & & ALF & 0 & 0.915 & 0 & 0 & 0 \\
\hline & & CINN & 0.994 & 0.037 & 0 & 0.182 & 0 \\
\hline & $\mathrm{CHX}$ & ALOF & 0 & 0 & 0 & 0 & 0 \\
\hline & & ALF & 0.541 & 0 & 0 & 0 & 0 \\
\hline & & CINN & 0.003 & 0 & 0 & 0.001 & 0 \\
\hline & ALOF & ALF & 0 & 0 & 0 & 0 & 0 \\
\hline & & CINN & 0 & 0 & 0 & 0 & 0 \\
\hline & ALF & CINN & 0 & 0.066 & 0 & 0 & 0 \\
\hline \multirow[t]{10}{*}{ Gold } & DW & $\mathrm{CHX}$ & 0.695 & 0 & 0 & 0 & 0 \\
\hline & & ALOF & 0 & 0 & 0 & 0 & 0 \\
\hline & & ALF & 0.920 & 0.872 & 0 & 0 & 0 \\
\hline & & CINN & 0 & 0 & 0 & 0 & 0 \\
\hline & $\mathrm{CHX}$ & ALOF & 0 & 0 & 0.815 & 0 & 0 \\
\hline & & ALF & 1.000 & 0 & 0 & 0 & 0 \\
\hline & & CINN & 0 & 0 & 0 & 0 & 0 \\
\hline & ALOF & ALF & 0 & 0 & 0 & 0 & 0 \\
\hline & & CINN & 0 & 0.143 & 0 & 0 & 0 \\
\hline & ALF & CINN & 0 & 0 & 0 & 0 & 0 \\
\hline
\end{tabular}

CHX: Chlorhexidine; CINN: Cinnamon 
Assessment of lons released from Three Types of Orthodontic Brackets

Table 3: Comparison of ions released between two types of brackets using Games-Howell test

\begin{tabular}{|c|c|c|c|c|c|c|c|}
\hline \multirow[b]{2}{*}{ Mouth washes } & \multirow[b]{2}{*}{ Bracket types } & & $\mathrm{Cr}$ & $\mathrm{Ni}$ & $F e$ & $M n$ & $\mathrm{Cu}$ \\
\hline & & & \multicolumn{5}{|l|}{$p$-value } \\
\hline \multirow[t]{3}{*}{ DW } & Pinnacle & Votion & 0.188 & 0.003 & 0 & 0.519 & 0.883 \\
\hline & & Gold & 0.976 & 0.001 & 0.953 & 0.790 & 0.877 \\
\hline & Votion & Gold & 0.262 & 0.023 & 0 & 0.611 & 0.679 \\
\hline \multirow[t]{3}{*}{$\mathrm{CHX}$} & Pinnacle & Votion & 0 & 0 & 0 & 0 & 0 \\
\hline & & Gold & 0 & 0 & 0 & 1 & 0 \\
\hline & Votion & Gold & 0.001 & 0 & 0 & 0 & 0 \\
\hline \multirow[t]{3}{*}{ ALOF } & Pinnacle & Votion & 0.918 & 0.004 & 0 & 0 & 0 \\
\hline & & Gold & 0 & 0 & 0.070 & 0 & 0 \\
\hline & Votion & Gold & 0 & 0 & 0 & 0 & 0.012 \\
\hline \multirow[t]{3}{*}{ ALO } & Pinnacle & Votion & 0 & 0 & 0 & 0 & 0 \\
\hline & & Gold & 0 & 0 & 0 & 0 & 0 \\
\hline & Votion & Gold & 0 & 0 & 0.529 & 0.001 & 0 \\
\hline \multirow[t]{3}{*}{ CINN } & Pinnacle & Votion & 0 & 0 & 0 & 0.078 & 0 \\
\hline & & Gold & 0 & 0 & 0 & 0 & 0 \\
\hline & Votion & Gold & 0 & 0 & 0 & 0 & 0 \\
\hline
\end{tabular}

CHX: Chlorhexidine; CINN: Cinnamon
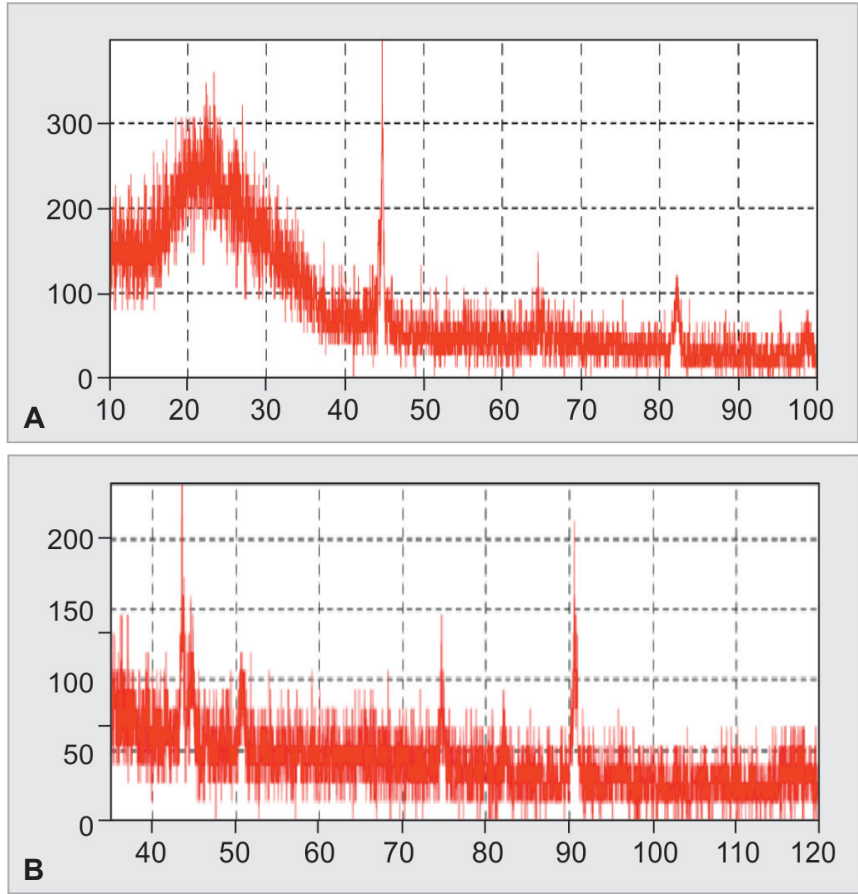

Graphs $1 \mathrm{~A}$ and $\mathrm{B}$ : The XRD of votion brackets

\section{Results of XRD Test}

For votion bracket type, XRD showed that the base is composed of $\mathrm{Cu}(82.2 \%)$ and $\mathrm{Ni}(17.8 \%)$, while the bracket is composed of $\mathrm{Co}(30 \%)$ and $\mathrm{Fe}(70 \%)$ or $\mathrm{Al}(50 \%)$ and $\mathrm{Ni}$ (50\%) (Graph 1). The result of this test for Pinnacle brackets was $\mathrm{Cr}(33.3 \%), \mathrm{Fe}(33.3 \%)$, and $\mathrm{Ni}(33.3 \%)$ (Graph 2), while gold type is coated with $100 \%$ pure gold (Graph 3), but XRD could not penetrate the coating layer and examine the inner components of brackets.

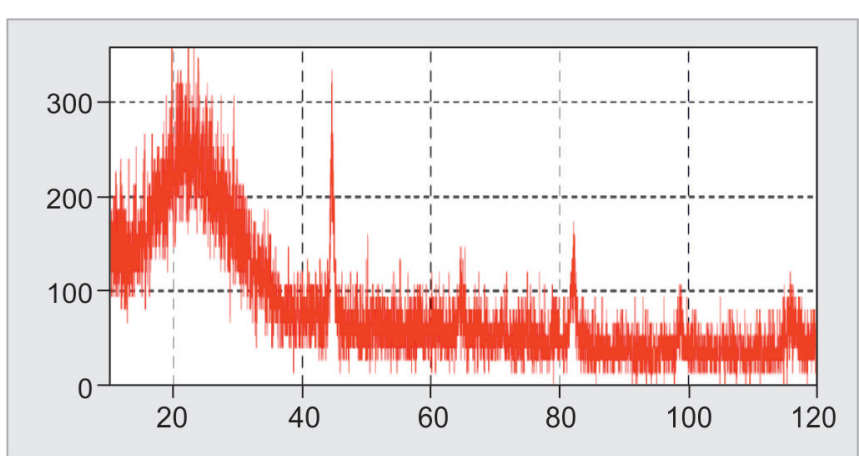

Graph 2: The XRD of Pinnacle brackets

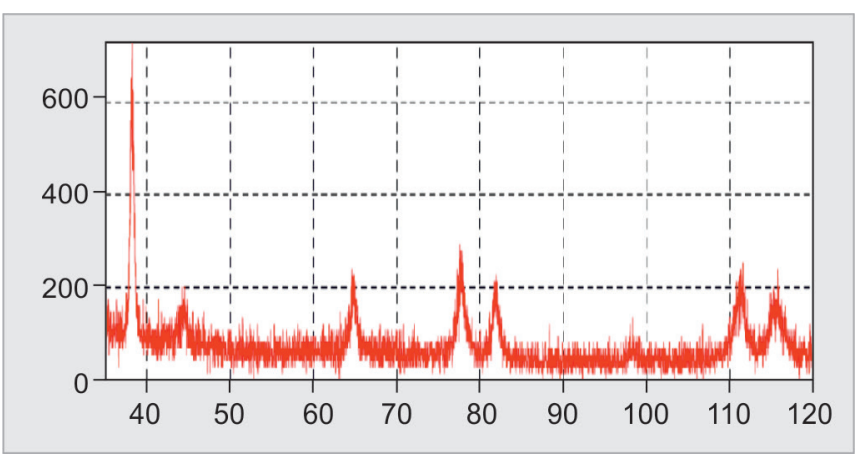

Graph 3: The XRD of gold brackets

\section{DISCUSSION}

In this study, three different types of brackets were used, namely, gold brackets which were stainless steel brackets plated with $24 \mathrm{~K}$ gold of one piece, votion brackets which were of two-piece system, and finally Pinnacle brackets (stainless steel one-piece system). Moreover, four types of mouthwashes were tested for ions release, and three 
of them were herbals as the medical trend now is toward herbs in medicine.

The brackets were immersed in mouthwash for 45 days according to Danaei et $\mathrm{al}^{13}$ as this period represented approximately the contact between the brackets and mouthwash during 2 years of fixed orthodontic treatment. According to Gwinnett, ${ }^{19}$ adhesive resin was omitted to eliminate any other source of ion release, both surfaces of the brackets (face and base) were subjected to the mouthwash accordingly, and the ions released were doubled.

Although being the first study that inspects the ions released by gold and metal injection mold brackets under the effect of herbal mouthwashes gives this research its uniqueness and novelty, it makes the comparison of results with other research difficult, and moreover, surface area of the brackets, methods of ion release measurement, and time of immersion have effect and differ among various studies.

In human mouth, normally metal is released in saliva, and the amount of metal released is affected by: (a) Salivary constituents which differ according to human health and day times; and (b) different foodstuffs and beverages of low $\mathrm{pH}^{20,21}$ Mouthwashes in the present study were used in static situation not dynamic like in actual life, so metal release may be less, also the state of saliva and teeth brushing that removes the oxide layer may have an effect. ${ }^{13}$

Ion release due to bracket corrosion is a classical problem in orthodontic treatment. Corrosion can be defined as a destructive phenomenon of metal or alloy by chemical or electrochemical changes. It takes several forms. First, overall surface attack slowly reduces the thickness or the weight of metal. Second, only isolated area affected produces localized corrosion. Third, corrosion occurs on grain boundaries or other lines of weakness. Metals or alloys tend to enter into chemical union with the elements of corrosive medium to form stable compounds similar to those present in nature (corrosive product). The physiochemical corrosion may be divided into seven categories: (i) Galvanic corrosion, (ii) intergranular corrosion, (iii) pitting corrosion, (iv) concentration cell corrosion, (v) stress corrosion, (vi) dezincification, and (vii) erosive-impingement corrosion. ${ }^{22,23}$

The factors found to be influencing on corrosion can be divided into ${ }^{24}$ internal corrosive factors (determined by metal composition, manufacturing method, and bracket surface characteristics) and external factors (which depend on media composition, $\mathrm{pH}$, temperature, strain, illumination, impurities, dissolved salts, and oxidizing agents). Even when the same alloys were used, different results were obtained; this may be due to variation in analytical techniques, such as different sensitivities, interferences, and detection limits.
The XRD has also been used in this research, and it relies on the dual-wave/particle nature of $X$-rays to obtain information about the structure of the crystalline materials. The scattered monochromatic $X$-rays from the target material undergo constructive and destructive interference, this is the process of diffraction. The direction of possible diffraction depends on the size and shape of the unit cell of the material. ${ }^{25}$

The intensities of the diffracted waves depend on the kind and arrangement of atoms in the crystal structure. Most materials are not single crystals but composed of many tiny crystallites in all possible orientations called a polycrystalline aggregate. When material with randomly oriented crystallites is placed in the X-ray beam, the beam will see all possible interatomic planes. If the experimental angle is systematically changed, all possible diffraction peaks from the material will be detected. ${ }^{26}$

The result of ion release in the present study, Table 1 (descriptive statistics) reveals no systematic pattern between bracket types or mouthwashes. Regarding ion release in different bracket type groups, gold and votion presented high concentrations of ions release than Pinnacle, and this could be attributed to the metallurgical process, manufacturing process, and microstructure reasons as well. ${ }^{4,21}$

The XRD of gold gave the outermost layer to be pure gold, and this layer was originally plated on the one-piece-casted bracket to increase resistant to wear, peeling, and chipping; nonetheless, the ion released after mouthwash immersion was conspicuous indicating that this top layer was not strong enough to resist corrosion. Gold bracket is thought to be affected by stress corrosion. Internal stress may be produced by nonuniform deformation during cold working (bending, shearing, and punching), by unequal cooling from high temperature, and by internal structure rearrangements involving volume change. This type of stress produced crack which accelerated corrosion. ${ }^{22}$

In votion (two-piece system bracket), 80-gauge micro-etched mesh bonding base was brazed together with stainless steel MIM body. High ion release might be related to the different elemental compositions of these two types of stainless steel, and the brazing alloy gives rise to variance in their corrosion potentials. ${ }^{27}$ The less stable metal tends to corrode and oxidize, releasing ions into the solution as it disintegrates. ${ }^{21,27}$ Furthermore, the shape and design of the base increased the surface area exposure; this increased the possibility to corrosion, especially concentration cell corrosion. This type of corrosion is associated with joints, gaskets, scales, and looseness of the protective film, and it is caused by a change in concentration of environments and acidity changes. ${ }^{22}$ The results showed Pinnacle as statistically significant 
in lower ion release in different mouthwashes, and this gave it the merit of being the most biocompatible bracket.

Regarding ions released in different mouthwashes, the ions released from the brackets in DW (control group) were attributed to the lack of ions in its content which made it a violent solvent. Distilled water is produced by vaporization and condensation which ensures high purity. Ideally, the water should be nothing but hydrogen and oxygen molecules, no additional gases, minerals, or contaminants. The corrosion of metals in water is affected by the oxygen content, the level of $\mathrm{pH}$, water temperature, and duration of immersion. The $\mathrm{pH}$ of DW (control) was 7.04, so it is not the acidity that may contribute to corrosion; DW in lack of minerals acts like a magnet absorbing ions from stainless steel, and this agrees with the studies of Danaei et $\mathrm{al}^{13}$ and Patel et $\mathrm{al}^{14}$ and yet in this study, it was not the highest corrosive solution as mentioned by these researches.

Certain ions, such as nickel and chromium can result in symptoms of toxicity and allergic reactions. ${ }^{28,29}$ The most significant human exposure to nickel and chromium occurs through diet. The average dietary intake of nickel and chromium is 200 to 300 and $280 \mu \mathrm{g} /$ day respectively. ${ }^{30}$ Nickel concentrations in drinking water generally measure below $20 \mu \mathrm{g} / \mathrm{L}$, while average chromium levels in drinking water are $0.43 \mu \mathrm{g} / \mathrm{L}$. The $\mathrm{Ni}$ and $\mathrm{Cr}$ ions released from orthodontic appliances in this study were insignificant when compared with the amount from daily food and water intake. Despite different study designs, these results show slightly lower concentrations than reported in other studies. ${ }^{13,31}$ In the present study, the means of ions released from every bracket in separate beakers were measured, but based on about 20 brackets in a patient's mouth in clinical use, the results might become clinically significant. ${ }^{13}$ In this study, ALOF mouthwash had the highest nickel and chromium ion release that could be the result of fluoride anion. In an acidic environment, corrosion could easily occur even with low fluoride concentrations, ${ }^{32}$ pitting type of corrosion is caused by anions, such as chloride and fluoride ions which attack the protective oxide layer. ${ }^{33}$

Manganese and copper were the highest in ALO mouthwash, although these results disagreed with Singh ${ }^{34}$ who found that ALO has inhibition efficiency of corrosion lying between 22 and $73 \%$ at different concentrations; however, there are several possible explanations for these results. It seems possible due to $\mathrm{Cu}$ ion percentage in the stainless steel alloy of bracket and the chemical composition of mouthwash. Aloe vera herb consisted of 75 nutrients including vitamins, enzymes, sugar, phenolic compounds, lignin, saponins, sterols, amino acids, and salicylic acid, and the minerals that are present are $\mathrm{Ca}$, $\mathrm{Mn}, \mathrm{Na}, \mathrm{K}, \mathrm{Cu}, \mathrm{Mg}, \mathrm{Z}, \mathrm{Cr}$, and Fe. ${ }^{35}$ This explains the results of increasing $\mathrm{Fe}, \mathrm{Mn}$, and $\mathrm{Cr}$ ions, especially for the last two ions where it is considered as main component of stainless steel alloy.

Iron was highly released under the strong corrosive evidence of cinnamon mouthwash, especially with gold bracket, and, i.e., due to its low $\mathrm{pH}$ value (2.83), which is one of the most important factors of corrosion combating process; furthermore, highly released ions might be correlated to the composition of cinnamon herb that 1 ounce of it contains iron (13\%), magnesium (4\%), copper (5\%) in addition to other minerals, vitamins, amino acids, and antioxidants, such as polyphenols, phenolic acid, and flavonoids. ${ }^{36}$ For the groups immersed in chlorhexidine, the finding observed in this study disagreed with those of previous studies that had examined the effect of chlorhexidine on orthodontic appliance showing high corrosive affinity, ${ }^{13,37}$ and it might be conjugated to its balanced $\mathrm{pH}$ value (7.10).

\section{CONCLUSION}

It can be concluded that mouthwash corrosiveness, which in turn depends on its chemical structure, and the bracket manufacturing process are major factors responsible for the release of metal ions from dental brackets. The amount of ions released in herbal mouthwashes is higher than chlorhexidine, so prolonged use of these mouthwashes is not recommended. Pinnacle bracket releases ions less than gold and votion brackets in the tested mouthwashes making it more biocompatible.

\section{REFERENCES}

1. Angle EH. The latest and best in orthodontic mechanisms. Dent Cosmos 1928 Dec;70(12):1143-1158.

2. Kerosuo H, Moe G, Hensten-Pettersen A. Salivary nickel and chromium in subjects with different types of fixed orthodontic appliances. Am J Orthod Dentofacial Orthop 1997 Jun;111(6):595-598.

3. Birnie, D.; Harradine, N. Excellence in orthodontics. 27th ed. London: Excellence in Orthodontics; 2016.

4. Matasa, CG. Characterization of used orthodontic brackets. In: Eliades G, Eliades T, Brantley WA, Watts DC, editors. Dental materials in vivo: aging and related phenomena. 1st ed. New York: Quintessence; 2003. pp. 141-156.

5. Floria G, Franchi L. Metal injection molding in orthodontics. Virtual J Orthod 1997 Oct;2:1.

6. Savarino L, Granchi D, Ciapetti G, Cenni E, Nardi Pantoli A, Rotini R, Veronesi CA, Baldini N, Giunti A. Ion release in patients with metal-on-metal hip bearings in total joint replacement: a comparison with metal-on-polyethylene bearings. J Biomed Mater Res 2002 Jul;63(5):467-474.

7. Matasa CG. Attachment corrosion and its testing. J Clin Orthod 1995 Jan;29(1):16-23.

8. Huang TH, Yen CC, Kao CT. Comparison of ion release from new and recycled orthodontic brackets. Am J Orthod Dentofacial Orthop 2001 Jul;120(1):68-75. 
9. Jasim ES, Garma NM, Thyab SA. Comparative assessment of in vitro effect of three fluoride releasing agents on enamel demineralization around orthodontic brackets. J Bagh Coll Dentistry 2016 Jun;28(2):126-133.

10. Justus, R. Iatrogenic effects of orthodontic treatment, decisionmaking in prevention, diagnosis, and treatment. 1st ed. Switzerland: Springer; 2015.

11. Peter, S. Essentials of preventive and community dentistry. 4th ed. New Delhi: Arya Medi Publishing House; 2009.

12. Brightman LJ, Terezhalmy GT, Greenwell H, Jacobs M, Enlow DH. The effects of a $0.12 \%$ chlorhexidine gluconate mouthrinse on orthodontic patients aged 11 through 17 with established gingivitis. Am J Orthod Dentofacial Orthop 1991 Oct;100(4):324-329.

13. Danaei SM, Safavi A, Roeinpeikar SM, Oshagh M, Iranpour S, Omidkhoda M. Ion release from orthodontic brackets in 3 mouthwashes: an in-vitro study. Am J Orthod Dentofacial Orthop 2011 Jun;139(6):730-734.

14. Patel R, Bhanat S, Patel D, Shah B. Corrosion inhibitory ability of Ocimum sanctum linn (Tulsi) rinse onion release from orthodontic brackets in some mouthwashes: an in vitro study. Natl J Community Med 2014 Jan-Mar;5(1):135-139.

15. Jamilian A, Moghaddas O, Toopchi S, Perillo L. Comparison of nickel and chromium ions released from stainless steel and NiTi wires after immersion in oral $\mathrm{B}^{\circledR}$, orthokin ${ }^{\circledR}$ and artificial saliva. J Contemp Dent Pract 2014 Jul-Aug;15(4):403-406.

16. Ahmed AG, Al-Sheakli II. An evaluation of ion released from two brands of brackets in three types of mouthwashes. J Bagh Coll Dentistry 2015 Dec;27(4):155-160.

17. Tahmasbi S, Ghorbani M, Masudrad M. Galvanic corrosion of and ion release from various orthodontic brackets and wires in a fluoride-containing mouthwash. J Dent Res Dent Clin Dent Prosp 2015 Summer;9(3):159-165.

18. Gajapurada J, Ashtekar S, Shetty P, Biradar A, Chougule A, Bhalkeshwar Bansal A, Zubair W. Ion release from orthodontic brackets in three different mouthwashes and artificial saliva: an in vitro study. IOSR J Dent Med Sci 2016 Apr;15(4): 76-85.

19. Gwinnett AJ. Corrosion of resin-bonded orthodontic brackets. Am J Orthod 1982 Jun;81(6):441-446.

20. Hwang CJ, Shin JS, Cha JY. Metal release from simulated fixed orthodontic appliances. Am J Orthod Dentofacial Orthop 2001 Oct;120(4):383-391.

21. von Fraunhofer JA. Corrosion of orthodontic devices. Semin Orthod 1997 Sep;3(3):198-205.

22. Charng T, Lansing F. Review of Corrosion Causes and Corrosion Control in a Technical Facility. TDA Prog Rep 1982 Mar-Apr;14:145-156.
23. Chaturvedi TP, Upadhayay SN. An overview of orthodontic material degradation in oral cavity. Indian J Dent Res 2010 Apr-Jun;21(2):275-284.

24. Kuhta M, Palvin D, Slaj M, Varga S, Lapter-Varga M, Slaj M. Type of arch wire and level of acidity: effects on the release of metal ions from orthodontic appliances. Angle Orthod 2009 Jan;79(1):102-110.

25. Shimadzu Corporation. XRD 6000: Shimadzu X-ray Diffractometer. Japan: Shimadzu Corporation; Available from: http://www.ssi.shimadzu.com/products/literature/xray/ xrd-6000.pdf.

26. Smart, LE.; Moore, EA. Chapter 2: Physical methods for characterizing solids. Boca Raton (FL): CRC Press; 2005. Available from: https:/ / www.unf.edu/ michael.lufaso/chem4627 / ch2_solid_state.pdf.

27. Fontana, MG. Corrosion engineering. 3rd ed. New York (NY): Mc-Graw Hill; 1987.

28. EliadesT,ZinelisS,PapadopoulosMA,EliadesG,AthanasiouAE. Nickel content of as-received and retrieved niTi and stainless steel arch wires: assessing the nickel release hypothesis. Angle Orthod 2004 Apr;74(2):151-154.

29. Eliades T, Athanasiou AE. In vivo aging of orthodontic alloys: implications for corrosion potential, nickel release, and biocompatibility. Angle Orthod 2002 Jun;72(3):222-237.

30. Kocadereli L, Ataç PA, Kale PS, Özer D. Salivary nickel and chromium in patients with fixed orthodontic appliances. Angle Orthod 2000 Dec;70(6):431-434.

31. Park HY, Shearer TR. In vitro release of nickel and chromium from simulated orthodontic appliances. Am J Orthod 1983 Aug;84(2):156-159.

32. Dartar Oztan M, Akman AA, Zaimoglu L, Bilgiç S. Corrosion rates of stainless-steel files in different irrigating solutions. Int Endod J 2002 Aug;35(8):655-659.

33. Schiff N, Dalard F, Lissac M, Morgon L, Grosgogeat B. Corrosion resistance of three orthodontic brackets: a comparative study of three fluoride mouthwashes. Eur J Orthod 2005 Dec;27(6):541-549.

34. Singh RK. Corrosion protection of stainless steel in vegetables by Aloe vera juice. Int J Appl Eng Technol 2012 Jul-Sep;2(3): 28-35.

35. Mangaiyarkarasi SP, Manigandan T, Elumalai M, Cholan PK, Kaur RP. Benefits of Aloe vera in dentistry. J Pharm Bioallied Sci 2015 Apr;7(Suppl 1):S255-S259.

36. Dr. AxeHealth benefits of cinnamon and nutrition facts. Available from: https://www.draxe.com/health-benefits-cinnamon.

37. Mandsaurwala M, Kalia A, Gupta G, Hegde A, Mirdehghan N. Comparative evaluation of ion release from orthodontic miniimplants in 2 mouthwashes: an in-vitro study. Int J Oral Health Dentistry 2015 Oct-Dec;1(4):177-181. 